\title{
Incidence and risk factors for postpartum hemorrhage in Uganda
}

Sam Ononge ${ }^{1 *}$, Florence Mirembe ${ }^{1}$, Julius Wandabwa ${ }^{2}$ and Oona M. R. Campbell ${ }^{3}$

\begin{abstract}
Background: Globally, postpartum haemorrhage (PPH) remains a leading cause of maternal deaths. However in many low and middle income countries, there is scarcity of information on magnitude of and risk factors for PPH (blood loss of $500 \mathrm{ml}$ or more). It is important to understand the relative contributions of different risk factors for PPH. We assessed the incidence of, and risk factors for postpartum hemorrhage among rural women in Uganda.

Methods: Between March 2013 and March 2014, a prospective cohort study was conducted at six health facilities in Uganda. Women were administered a questionnaire to ascertain risk factors for postpartum hemorrhage, defined as a blood loss of $500 \mathrm{mls}$ or more, and assessed using a calibrated under-buttocks drape at childbirth. We constructed two separate multivariable logistic regression models for the variables associated with PPH. Model 1 included all deliveries (vaginal and cesarean sections). Model 2 analysis was restricted to vaginal deliveries. In both models, we adjusted for clustering at facility level.
\end{abstract}

Results: Among the 1188 women, the overall incidence of postpartum hemorrhage was $9.0 \%$, (95\% confidence interval [Cl]: 7.5-10.6\%) and of severe postpartum hemorrhage (1000 mls or more) was 1.2\%, (95\% Cl 0.6-2.0\%). Most (1157 [97.4\%]) women received a uterotonic after childbirth for postpartum hemorrhage prophylaxis. Risk factors for postpartum hemorrhage among all deliveries (model 1) were: cesarean section delivery (adjusted odds ratio [aOR] 7.54; $95 \% \mathrm{Cl}$ 4.11-13.81); multiple pregnancy (aOR 2.26; $95 \% \mathrm{Cl}$ 0.58-8.79); foetal macrosomia $\geq 4000 \mathrm{~g}$ (aOR 2.18; $95 \% \mathrm{Cl} 1.11-4.29$ ); and HIV positive sero-status (aOR 1.93; $95 \% \mathrm{Cl}$ 1.06-3.50). Risk factors among vaginal deliveries only, were similar in direction and magnitude as in model 1, namely: multiple pregnancy, (aOR 7.66; $95 \% \mathrm{Cl}$ 1.81-32.34); macrosomia, (aOR 2.14; $95 \%$ Cl1.02-4.47); and HIV positive sero-status (aOR 2.26; $95 \% \mathrm{Cl}$ 1.20-4.25).

Conclusion: The incidence of postpartum hemorrhage was high in our setting despite use of uterotonics. The risk factors identified could be addressed by extra vigilance during labour and preparedness for PPH management in all women giving birth.

Keywords: Labor, Oxytocics, Pregnancy, Postpartum hemorrhage, Risk factors

\section{Background}

Globally, postpartum hemorrhage (PPH) is a leading cause of maternal mortality [1]. The global prevalence of PPH is $6 \%$ [2] and the highest burden is experienced in low-income countries $[3,4]$. The magnitude of PPH in sub-Saharan Africa is high at $10.5 \%$ [2]. In Uganda, PPH causes $25 \%$ of all maternal deaths [5]. However, there is little information on the magnitude and risk factors for PPH. Common causes of PPH are uterine atony,

\footnotetext{
* Correspondence: ononge2006@yahoo.com

'Department of Obstetrics and Gynaecology, Makerere University College of Health Sciences, P.O. Box 7072, Kampala, Uganda

Full list of author information is available at the end of the article
}

genital tract injuries, failure of the blood coagulation system and trauma. Uterine atony is responsible for the majority (75 \%) of PPH [6]. Risk factors for PPH include; past history of $\mathrm{PPH}$, multiple pregnancy, fetal macrosomia, primi-gravida, grand multi-parity, older age, preterm births, genital tract injuries, non-use of oxytocics for $\mathrm{PPH}$ prophylaxis, labour induction, cesarean birth and intra-uterine fetal deaths [4, 7-10]. However, majority of these studies visually estimated blood loss, a method that has considerable inaccuracy [11]. The few studies that have objectively measured blood loss after childbirth are in high-income countries, whose delivery 
settings differ from those in low income countries [12]. This study used a calibrated under-buttocks drape to measure blood loss that is highly correlated with the goldstandard measure of photospectometry [13]. Knowledge of the risk factors would inform public health interventions for PPH control. To the clinicians, risk factor identification in the antenatal and intrapartum periods may provide an opportunity for timely interventions to prevent $\mathrm{PPH}$. The present study was undertaken to objectively assess the incidence and risk factors for PPH among women in rural health facilities in Uganda.

\section{Methods}

Uganda's health system has 7 facility levels. As part of a stepped-wedge cluster-randomized trial on prevention of PPH using misoprostol (Registered in Pan African Clinical Trials Network: PACTR201303000459148), a prospective cohort study was conducted among women who delivered at six lower level health facilities (5 health centre IIIs and one health centre IV) in Mpigi district, Central Uganda between 6th March 2013 and 19th March 2014 [14]. The health centre IIIs, serve a sub-county with average population of 25,000 people [15], and are staffed by clinical officers, nurses, midwives, laboratory technician, and a health inspector. Maternity services offered at health centre III are basic essential obstetric care. In addition, these health facilities offer prevention of mother to child transmission of Human Immune deficiency virus (HIV) services which encompasses routine counseling and testing of all women attending the antenatal clinic. Those found HIV positive are routinely offered highly active anti-retroviral therapy provided by government of Uganda [16]. Medical high risk and complicated obstetric cases from health centre IIIs are referred to either health centre IVs or to hospitals (levels V-VII). Health centre IVs serve a health subdistrict with average population of 95,000. They are staffed as for Health centre III with the addition of a medical officer(s) and an anaesthetic officer. Health centre IVs provide comprehensive essential obstetric care, including caesarean section [17]. The six health centers in the study were purposively selected out of 9 eligible health facilities according to the trial inclusion criteria. Ethical approval was obtained from the School of Medicine Research and Ethics Committee at Makerere University, Kampala, Uganda, and the Uganda National Council for Science and Technology. Informed written consent was obtained from all participants at enrolment.

\section{Data collection}

Pregnant women were recruited at 28 weeks gestation or greater. The trial included women who planned to stay in the district during pregnancy, delivery and in the immediate postpartum period. The study excluded women who had a planned elective caesarean-section delivery or who had previous caesarean-section scars. The participants who delivered at the six health facilities were included in this study. Women who had missing data for the primary outcome of blood loss (16.6\%) were excluded in the analysis (Fig. 1). The health providers in the delivery rooms in these health facilities were trained on the data collection procedure and on measurement of postpartum blood loss. During enrolment, interviewer-administered questionnaires were used to collect data on the risk factors including: previous history of PPH, woman's age in completed years, parity and HIV sero-status obtained from patient records. Participants' hemoglobin levels were measured using a potable hemoCue ${ }^{\mathrm{R}} \mathrm{Hb} 301$ system at recruitment. Gestational age at birth was calculated based on ultrasound scan estimation, the self-report of last normal menstrual period (LNMP), or fundal height estimation. The research team noted whether labour was induced or augmented with oxytocin, the mode of delivery, performance of episiotomy, perineal tear requiring suture, single or multiple deliveries, use of oxytocics at birth to prevent PPH (injectable oxytocin $10 \mathrm{IU}$ or oral misoprostol 600 micrograms) within 1 min of delivery. Birth weight was measured using a Seca Medical 725 mechanical baby scale. The primary outcome was postpartum hemorrhage defined as blood loss of $500 \mathrm{mls}$ or more after childbirth, while severe postpartum hemorrhage was a blood loss of $1000 \mathrm{mls}$ or more. In women who had vaginal birth, postpartum blood loss was measured using a calibrated under-buttocks VBRASSS drape [13]. After delivery of the baby and clamping of the umbilical cord, a drape was placed under the woman's buttocks. Blood was allowed to flow into the drape for an hour or until the attending midwife felt that the flow of blood is inconsequential. The total blood loss collected in the calibrated conical receptacle was established by the attending midwife. The used drapes with their contents were disposed of correctly by the attending midwife. In women who had cesarean section, we relied on the visual estimation of blood loss by the operating clinician.

\section{Statistical analysis}

Data were double entered in Epidata 3.1, cleaned and exported to STATA 12 for analysis. Descriptive statistics provided the average blood loss and incidence of $\mathrm{PPH}$. The incidence of PPH in the first hour (immediate) postpartum was calculated as total number of women with blood loss of $500 \mathrm{ml}$ or more, divided by the total study sample and, was presented as a percentage. Characteristics that were continuous and categorical variables were calculated as means and proportions respectively. Bivariate logistic regression analysis of the risk factors for $\mathrm{PPH}$ was done to estimate crude odds ratios (cORs) and their $95 \%$ confidence interval. We constructed two separate multivariable logistic regression models for the variables 


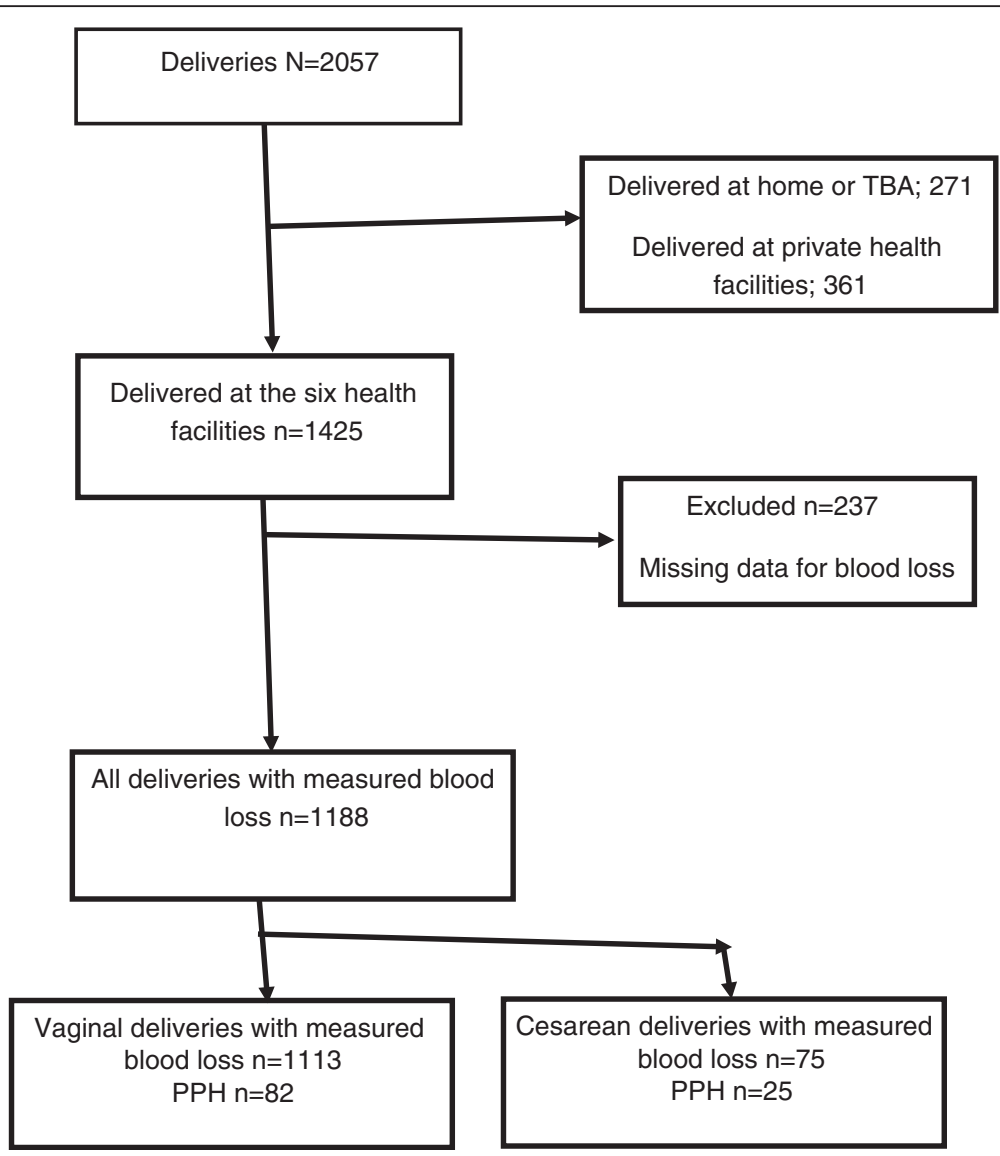

Fig. 1 Profile of the study participants

associated with PPH. Model 1 included all deliveries (vaginal and cesarean sections). Model 2 analysis was restricted to only vaginal deliveries. Factors that had a pvalue less than 0.2 at bivariate analysis were entered into multivariable logistic regression analysis to estimate the adjusted odds ratios (aORs). In model 1 , covariates adjusted for in multivariable logistic regression included parity, maternal anaemia, past history of PPH, HIV serostatus, mode of delivery, multiple pregnancy, macrosomia (4000 g or more) and perineal tears. In model 2, mode of delivery was omitted. Because the participants in the study were from 6 clusters (health facilities), we adjusted for clustering in the logistic regression. A statistical significance was defined as a $\mathrm{p}$ value $<0.05$.

We estimated that with prevalence of PPH of $6 \%$, a sample size of 1171 women would give a $90 \%$ power to detect a $40 \%$ increased risk for PPH in grand-multiparous women [2].

\section{Results}

Data collected among 1188 women showed mean blood loss of $236 \mathrm{ml}( \pm 193 \mathrm{ml})$ and ranged from 50 to 1800 mls. Overall, 107 (9.0 \%, $95 \%$; CI 7.5-10.6 \%) women had $\mathrm{PPH}$ and 14 (1.2 \%, $95 \%$; CI 0.6-2.0 \%) had severe
PPH (1000 mls or more). Table 1 shows the distribution of socio-demographic, antepartum and intrapartum characteristics of the study participants, and their association with $\mathrm{PPH}$. In general women with PPH tended to be older, more likely to have twin births and HIV infection. They were also more likely to have delivered a macrosomic baby, be postdates or have received no uterotonic. Overall, only 31 (2.6\%) women did not receive a uterotonic at childbirth for $\mathrm{PPH}$ prevention. Main reasons for not receiving uterotonic at birth were facility stock outs of drugs and syringes. Among those who did receive uterotonics, oxytocin was the most frequent drug administered. Out of the $82(6.9 \%)$ women who received additional uterotonics at birth, majority (78) got misoprostol. Women who had PPH were more than twice more likely to have received additional uterotonic than those who did not have PPH (14.0 \% vs $6.2 \%)$. The prevalence of PPH and severe PPH among the 1113 women with vaginal deliveries were $7.4 \%$ and $0.7 \%$ respectively. Seven $(0.6 \%)$ women received blood transfusion after childbirth, while 6 $(0.5 \%)$ were referred to hospital because of lack of blood products at the study facility.

In model 1 that included both the vaginal and cesarean deliveries Table 1, factors associated with 
Table 1 Association between the risk factors and postpartum hemorrhage among all deliveries

\begin{tabular}{|c|c|c|c|c|c|c|}
\hline Variable & No PPH $(n=1,081)^{\mathrm{a}}$ & $\operatorname{Had} \mathrm{PPH}(n=107)^{\mathrm{a}}$ & Crude OR (95\% Cl) & $P$ value & Adjusted OR (95 \% Cl) & $P$ value \\
\hline \multicolumn{7}{|l|}{ Parity } \\
\hline Primiparous & $301(27.8)$ & $31(29.0)$ & $0.97(0.61-1.53)$ & 0.47 & $0.85(0.49-1.44)$ & 0.30 \\
\hline $2-4$ & $545(50.4)$ & $58(54.2)$ & Reference & & Reference & \\
\hline $5+$ & $235(21.7)$ & $18(16.8)$ & $0.72(0.42-1.25)$ & & $0.64(0.34-1.15)$ & \\
\hline Previous history of PPH & $47(4.4)$ & $9(8.4)$ & $2.02(0.96-4.24)$ & 0.06 & $1.86(0.81-4.26)$ & 0.16 \\
\hline \multicolumn{7}{|l|}{ Gestation age at birth (weeks) } \\
\hline Preterm $(<37)$ & $181(16.7)$ & $16(15.0)$ & $0.90(0.51-1.58)$ & 0.76 & $0.80(0.44-1.46)$ & 0.71 \\
\hline Term (37-41) & $762(70.5)$ & $75(70.1)$ & Reference & & Reference & \\
\hline Post term (>41) & $138(12.8)$ & $16(15.0)$ & $1.18(0.67-2.08)$ & & $1.07(0.58-1.99)$ & \\
\hline Multiple pregnancy & $10(0.9)$ & $4(3.7)$ & $4.16(1.28-13.50)$ & 0.02 & $2.26(0.58-8.79)$ & 0.26 \\
\hline Moderate-severe anemia in pregnancy & $121(11.2)$ & $15(14.0)$ & $1.14(0.85-1.52)$ & 0.38 & $0.99(0.72-1.35)$ & 0.97 \\
\hline HIV positive & $98(9.1)$ & $17(15.9)$ & $1.89(1.08-3.31)$ & 0.03 & $1.93(1.06-3.50)$ & 0.04 \\
\hline Cesarean-section birth & $50(4.6)$ & $25(23.4)$ & $6.29(3.70-10.68)$ & $<0.001$ & $7.54(4.11-13.81)$ & $<0.001$ \\
\hline Labour induction/augmented & $42(3.9)$ & $3(2.8)$ & $0.71(0.22-2.34)$ & 0.58 & & \\
\hline Macrosomia $\geq 4000 \mathrm{gm}$ & $78(7.2)$ & 15(14.0) & $2.10(1.16-3.79)$ & 0.01 & $2.25(1.14-4.43)$ & 0.03 \\
\hline No uterotonic at birth & $25(2.3)$ & $6(5.6)$ & $2.51(1.01-6.26)$ & 0.05 & $2.23(0.80-6.21)$ & 0.14 \\
\hline Additional uterotonic & $67(6.2)$ & $15(14.0)$ & & & & \\
\hline Episiotomy/Perineal tear & $133(12.3)$ & $13(12.1)$ & $0.99(0.54-1.81)$ & 0.96 & $1.44(0.71-2.94)$ & 0.32 \\
\hline
\end{tabular}

Abbreviation: PPH Postpartum hemorrhage, $\mathrm{OR}$ odds ratio, $\mathrm{Cl}$ confidence interval, HIV Human Immunodeficiency Virus

${ }^{a}$ Values are given as numbers (percentages)

increased risk for PPH included: HIV sero positivity (aOR 1.93; 95 \% CI 1.06-3.50); cesarean section (aOR $7.54 ; 95 \%$ CI 4.11-13.81); and fetal macrosomia $\geq 4000 \mathrm{~g}$ (aOR 2.18; 95 \% CI 1.11-4.29). Multiple pregnancy and no uterotonic after childbirth, though significant at unadjusted analysis, were not associated with $\mathrm{PPH}$ after controlling for other risk factors. In the second model (only vaginal deliveries) Table 2, factors associated with increased risk for $\mathrm{PPH}$ at logistic regression analysis included: HIV sero positivity (aOR 2.26; $95 \%$ CI 1.20-4.25); multiple pregnancy (aOR 7.66; $95 \%$ CI 1.8132.34 ); and fetal macrosomia $\geq 4000 \mathrm{~g}$ (aOR 2.14; $95 \% \mathrm{CI}$ $1.02-4.47)$. On the other hand, grand multi-parity was marginally associated with PPH $(p=0.07)$.

All 14 (1.2\%) participants who developed severe $\mathrm{PPH}$ received fluid replacement. Five women were given additional oxytocin, two received blood transfusion and two were transferred from health centre III to hospital; unfortunately one died en-route. Of all participants who developed severe $\mathrm{PPH}$, six were delivered by cesarean section, and one was among those transfused. One woman had cervical tear that was successfully repaired in theatre under general anesthesia.

\section{Discussion}

This study demonstrated that, almost all (97 \%) women delivering at the six health facilities in rural Uganda received a uterotonic for prevention of $\mathrm{PPH}$. The overall incidence of $\mathrm{PPH}$ was $9.0 \%$ and of severe $\mathrm{PPH}$ was $1.2 \%$. The risk factors for PPH were being HIV positive, multiple pregnancy, delivery by cesarean section and delivering a macrosomic baby. The study minimized classification bias of PPH by objectively measuring the blood loss after child-birth using a calibrated drape.

The incidence of $\mathrm{PPH}$ in this study is higher than the reported global rate of $6 \%$ by Carroli et al [2], however similar incidence of $10.8 \%$ was reported by Calvert et al [12]. This high incidence of $\mathrm{PPH}$ in this study may have been influenced by the characteristics of the study population; these were rural women that are reported to have higher rates of PPH. Studies that have compared urban and rural women have reported higher rates of $\mathrm{PPH}$ in the later $[2,18]$. The high rates in rural areas could be related to substandard care. It is also possible that the use of calibrated drape in assessment of postpartum bleeding could have influenced the apparent high rate of $\mathrm{PPH}$ since assessment of postpartum blood loss using a calibrated drape is more objective way of determining the rate of $\mathrm{PPH}$. Most studies that report lower rates of $\mathrm{PPH}$ have used visual estimation of blood loss [4] which is known to underestimate the amount of measured blood loss by $30 \%$ [11]. Nevertheless since this study found that the vast majority of women received oxytocin, it is somewhat surprising that PPH was so high. This raises concern about the cold chain maintenance for the storage of oxytocin in rural settings where 
Table 2 Association between the risk factors and postpartum hemorrhage in vaginal deliveries ${ }^{a}$

\begin{tabular}{|c|c|c|c|c|c|c|}
\hline Variable & No PPH $n=1,031(\%)$ & $\mathrm{PPH} \geq 500 \mathrm{mls} n=82(\%)$ & Crude OR (95 \% Cl) & $P$ value & Adjusted OR (95\% Cl) & $P$ value \\
\hline Age in years & & & & 0.89 & & \\
\hline$\leq 19$ & 199 (19.3) & $17(20.7)$ & $1.11(0.63-1.95)$ & & & \\
\hline $20-34$ & $754(73.1)$ & $58(70.7)$ & Ref & & & \\
\hline$>34$ & $78(7.6)$ & $7(8.5)$ & $1.17(0.51-2.64)$ & & & \\
\hline Mean age (standard deviation) & $24.5(5.7)$ & $24.4(6.0)$ & & 0.93 & & \\
\hline Married & $902(87.5)$ & $68(82.9)$ & $0.69(0.38-1.27)$ & 0.24 & & \\
\hline Grand multi-Parity & $230(22.3)$ & $14(17.1)$ & $0.72(0.40-1.30)$ & 0.27 & $0.57(0.31-1.08)$ & 0.07 \\
\hline Past history of $\mathrm{PPH}$ & $45(4.4)$ & $9(11.0)$ & $2.7(1.27-5.74)$ & 0.01 & $2.08(0.89-4.85)$ & 0.11 \\
\hline Gestational age at birth & & & & 0.82 & & 0.84 \\
\hline Preterm (<37 weeks) & $170(16.5)$ & $12(14.6)$ & $0.89(0.47-1.69)$ & & $0.85(0.43-1.67)$ & \\
\hline Term (37-41 weeks) & $730(70.8)$ & $58(70.7)$ & Reference & & Reference & \\
\hline Post term (>41 weeks) & $131(12.7)$ & $12(14.6)$ & $1.15(0.60-2.21)$ & & $1.08(0.54-2.16)$ & \\
\hline Multiple pregnancy & $6(0.6)$ & $4(4.9)$ & $8.76(2.42-31.7)$ & 0.001 & $7.66(1.81-32.34)$ & 0.01 \\
\hline Anaemia in pregnancy & & & & 0.58 & & 0.84 \\
\hline No anaemia & $696(67.5)$ & $53(64.6)$ & Reference & & Reference & \\
\hline Mild anaemia & $225(21.8)$ & $17(20.7)$ & $1.06(0.64-1.75)$ & & $0.97(0.58-1.62)$ & \\
\hline Moderate-severe anaemia & $110(10.7)$ & $12(14.6)$ & $1.72(0.65-4.57)$ & & $1.37(0.47-3.98)$ & \\
\hline HIV positive & $92(8.9)$ & $15(18.3)$ & $2.29(1.25-4.16)$ & 0.007 & $2.26(1.20-4.25)$ & 0.02 \\
\hline Macrosomia $\geq 4000 \mathrm{~g}$ & $75(7.3)$ & $10(12.2)$ & $1.77(0.88-3.57)$ & 0.87 & $2.14(1.02-4.47)$ & 0.04 \\
\hline Uterotonic after birth & & & & 0.02 & & 0.31 \\
\hline None & $25(2.4)$ & $6(7.3)$ & $4.12(1.22-13.8)$ & & $2.80(0.75-10.4)$ & \\
\hline Oxytocin & $903(87.6)$ & $70(85.4)$ & Reference & & Reference & \\
\hline Misoprostol & $103(10)$ & $6(7.3)$ & $1.32(0.56-3.13)$ & & $1.36(0.56-3.27)$ & \\
\hline Additional uterotonic & $67(6.5)$ & $14(17.1)$ & $2.96(1.58-5.54)$ & 0.001 & & \\
\hline $\begin{array}{l}\text { Labor induced/ augmented } \\
\text { with oxytocin }\end{array}$ & $37(3.6)$ & $1(1.2)$ & $0.33(0.04-2.45)$ & 0.28 & & \\
\hline Episiotomy/Perineal tear & $131(12.7)$ & $13(15.9)$ & $1.29(0.70-2.41)$ & 0.42 & $1.44(0.73-2.83)$ & 0.29 \\
\hline
\end{tabular}

electricity is not readily available. A national survey done in 2007 on active management of the third stage of labour found that $34.3 \%$ of health facilities were storing oxytocin at room temperature [19]. Using an alternative uterotonic such as misoprostol that can be stored at room temperature would be an option to consider in setting with unstable electricity supply. However, we noted that in our study, women getting misoprostol versus oxytocin for prophylaxis had a $36 \%$ increased odds of PPH. Delivery by cesarean section was associated with increased risk of PPH. This is consistent with previous studies that report cesarean births being associated with increased risk of PPH $[4,6,20]$. However, few studies report a protective effect of cesarean section against $\mathrm{PPH}$ when compared to vaginal births $[21,22]$. The lower rates of PPH in cesarean section than in vaginal birth are in studies that included participants not in labor. In our study, the cesarean sections were performed in women who were in labor and where the operative mode of delivery was decided by attending physician for the good of the unborn baby and woman, with some of the cesarean sections probably being done late in advanced stages of labour. There is increased risk of severe $\mathrm{PPH}$ when cesarean sections are performed when the cervical dilatation is more than $9 \mathrm{~cm}$ or in second stage of labor mainly due to avulsion of the blood vessels at the delivery of impacted presenting part [23]. Our finding support existing evidence showing that cesarean section increases the risk of $\mathrm{PPH}[2,4,6,20,24]$. Cesarean section also increases risk of uterine atony, a leading cause of $\mathrm{PPH}$ $[6,25]$. Because women undergoing cesarean section are at increased risk of $\mathrm{PPH}$, health units performing them should have blood bank capacity to respond to a need for blood transfusion when required. In addition, its important for clinicians to re-assess the women destined for emergency cesarean section when near or in second stage of labour for possible instrumental vaginal (vacuum extraction or forceps) delivery. These modes of delivery have been observed to reduce the rates of cesarean section [26]. 
The risk of $\mathrm{PPH}$ was doubled in large (macrosomia, $\geq 4000 \mathrm{~g}$ ) babies. The increased risk of $\mathrm{PPH}$ among women giving birth to large babies has also been documented in previous studies [8, 9]. Large babies are known to over-distend the uterus which is associated with uterine atony. This findings call for more vigilance on the part of practitioners attending labor and births to identify women at risk, have adequate preparation and plan for early intervention to prevent PPH. Multiple pregnancy was associated with increased risk of PPH. This is consistent with previous studies that report multiple pregnancy being associated with $\mathrm{PPH}[6,10,20,25,27]$. The over distension caused by multiple pregnancy increases the risk of uterine atony. In addition, the large placental size in multiple increases the surface area for bleeding after childbirth.

Our findings showed that HIV positive pregnant women were more likely to have PPH than HIV negative, even in the analysis among vaginal births alone. Though a review of literature show that there is no significant difference in $\mathrm{PPH}$ rates between HIV positive and negative women [28], one subsequent study showed an increased risk of severe PPH among HIV positive women [29]. While the mechanism through which HIV causes $\mathrm{PPH}$ is not yet known, some have suggested that the increased thrombocytopenia that is observed in 10-30\% of HIV positive persons might be the one responsible for hemorrhage [30, 31]. Alternatively, it has been suggested that low level of care offered to HIV positive women at birth [28] could be responsible for the increased risk, whereby the health providers might be hesitant to implement an intervention when bleeding starts for fear of exposing themselves especially when there is no adequate protective gear. Our findings add to the growing body of knowledge, highlighting the impact of HIV on the health of women. This has clinical implications for the care of HIV positive pregnant in setting with high prevalence of HIV. There is a need for more research to further elucidate the problem and establish the mechanisms whereby HIV may lead to PPH.

This study had the following limitations. First, the findings are from health facilities and almost all women received a uterotonic. It is known in Uganda that $48 \%$ of deliveries occur at home [32]. Thus, the findings may not be generalizable to home deliveries. However, with exception of one study site (Health Centre IV), the study was conducted in lower level health facilities where services like blood transfusion and surgery (cesarean section) are not offered. Secondly, women who delivered by cesarean section had blood measured by visual estimation that has been known to underestimate blood loss. However, these were 75 (6\%), and are unlikely to have substantially affected the estimate of PPH risk. Thirdly there were only 14 cases with severe PPH. The study did not have adequate power to identify risk factors for severe $\mathrm{PPH}$.

\section{Conclusion}

The incidence of $\mathrm{PPH}$ was high despite many women receiving uterotonic at delivery of the babies. The risk factors for $\mathrm{PPH}$ in our setting were cesarean section, multiple pregnancy, fetal macrosomia and HIV. Extra vigilance during the antenatal and peripartum periods is needed to identify women at risk and early intervention to prevent $\mathrm{PPH}$. It is important to remember that we have to prepare for $\mathrm{PPH}$ in all women giving birth, as some get PPH without any known risk factors.

\section{Abbreviations}

Hb: Haemoglobin; HC: Health Centre; HIV: Human Immune-deficiency Virus; LNMP: Last Normal Menstrual Period; PPH: Postpartum Haemorrhage; WHO: World Health Organisation.

Competing interests

The authors declare that they have competing interests.

\section{Author's contributions}

$\mathrm{SO}$, and FM participated in the conception and design of the study. SO collected and analyzed the data. SO, OC, JW and FM interpreted the data. SO and FM drafted the initial manuscript. All the authors read, contributed and approved the final manuscript.

\section{Acknowledgement}

The study was supported by Training Health Researchers into Vocational Excellence in East Africa (THRIVE), funded by Wellcome Trust Grant Number: 087540. The contents of the paper are solely the responsibility of the authors and do not necessarily represent the official views of the supporting office. We gratefully acknowledge the help and corporation extended by administrators of Mpigi District, staff of the participated health units and the research team.

\section{Author details}

${ }^{1}$ Department of Obstetrics and Gynaecology, Makerere University College of Health Sciences, P.O. Box 7072, Kampala, Uganda. ${ }^{2}$ Department of Obstetrics and Gynaecology, Busitema University Faculty of Health Sciences, Mbale, Uganda. ${ }^{3}$ Faculty of Epidemiology and Population Health, London School of Hygiene and Tropical Medicine, London, UK.

Received: 21 January 2016 Accepted: 24 March 2016

Published online: 14 April 2016

\section{References}

1. Say L, Chou D, Gemmill A, Tuncalp O, Moller AB, Daniels J, Gulmezoglu AM, Temmerman M, Alkema L. Global causes of maternal death: a WHO systematic analysis. Lancet Glob Health. 2014;2:e323-333.

2. Carroli G, Cuesta C, Abalos E, Gulmezoglu AM. Epidemiology of postpartum haemorrhage: a systematic review. Best Pract Res Clin Obstet Gynaecol. 2008;22:999-1012.

3. AbouZahr C. Global burden of maternal death and disability. Br Med Bull. 2003;67:1-11.

4. Sheldon WR, Blum J, Vogel JP, Souza JP, Gulmezoglu AM, Winikoff B, Maternal WHOMSo, Newborn Health Research N. Postpartum haemorrhage management, risks, and maternal outcomes: findings from the World Health Organization Multicountry Survey on Maternal and Newborn Health. BJOG. 2014;121 Suppl 1:5-13

5. Road map for accelerating reduction in maternal and neonatal mortality and morbidity in Uganda. [cited 20 March 2015]. Available at URL: http://www.nationalplanningcycles.org/sites/default/files/country_docs/ Uganda/uganda_mnh_roadmap_2007-2015.pdf 
6. Lutomski JE, Byrne BM, Devane D, Greene RA. Increasing trends in atonic postpartum haemorrhage in Ireland: an 11-year population-based cohort study. BJOG. 2012;119:306-14.

7. Oberg AS, Hernandez-Diaz S, Palmsten K, Almqvist C, Bateman BT. Patterns of recurrence of postpartum hemorrhage in a large population-based cohort. Am J Obstet Gynecol. 2014;210:229. e221-228.

8. Bais JM, Eskes M, Pel M, Bonsel GJ, Bleker OP. Postpartum haemorrhage in nulliparous women: incidence and risk factors in low and high risk women. A Dutch population-based cohort study on standard (> or $=500 \mathrm{ml}$ ) and severe $(>$ or $=1000 \mathrm{ml}$ ) postpartum haemorrhage. Eur J Obstet Gynecol Reprod Biol. 2004;115:166-72.

9. Sheiner E, Sarid L, Levy A, Seidman DS, Hallak M. Obstetric risk factors and outcome of pregnancies complicated with early postpartum hemorrhage: a population-based study. J Matern Fetal Neonatal Med. 2005;18:149-54.

10. Sosa CG, Althabe F, Belizan JM, Buekens P. Risk factors for postpartum hemorrhage in vaginal deliveries in a Latin-American population. Obstet Gynecol. 2009;113:1313-9.

11. Al Kadri HM, Al Anazi BK, Tamim HM. Visual estimation versus gravimetric measurement of postpartum blood loss: a prospective cohort study. Arch Gynecol Obstet. 2011;283:1207-13.

12. Calvert C, Thomas SL, Ronsmans C, Wagner KS, Adler AJ, Filippi V. Identifying regional variation in the prevalence of postpartum haemorrhage: a systematic review and meta-analysis. PLoS One. 2012;7:e41114.

13. Patel A, Goudar SS, Geller SE, Kodkany BS, Edlavitch SA, Wagh K, Patted SS, Naik VA, Moss N, Derman RJ. Drape estimation vs. visual assessment for estimating postpartum hemorrhage. Int J Gynaecol Obstet. 2006;93:220-4.

14. Ononge S, Campbell OM, Kaharuza F, Lewis JJ, Fielding K, Mirembe F. Effectiveness and safety of misoprostol distributed to antenatal women to prevent postpartum haemorrhage after child-births: a stepped-wedge cluster-randomized trial. BMC Pregnancy Childbirth. 2015;15:315.

15. UBOS. National Population and Housing Census 2014. http://www.ubosorg/ onlinefiles/uploads/ubos/NPHC/NPHC\%202014\%20PROVISIONAL\%20 RESULTS\%20REPORT.pdf Cited November 29, 2015.

16. $\mathrm{MOH}$. The Intergrated National Guidelines on Antiretroviral Therapy Prevention of Mother to Child Transmission of HIV Infant \& Young Child Feeding 2012. http://library.health.go.ug/publications/service-deliverydiseases-control-prevention-communicable-diseases/hivaids/integrated Accessed January 2016.

17. $\mathrm{MOH}$. Health Sub-districts in Uganda. Concept paper. http://library.health.go. ug/publications/leadership-and-governance-governance/policy-documents/ health-sub-districts-concept. Cited on November 2015.

18. Li X, Zhu J, Dai L, Li M, Miao L, Liang J, Wang Y. Trends in maternal mortality due to obstetric hemorrhage in urban and rural China, 1996-2005. J Perinat Med. 2011;39:35-41.

19. Active management of third stage of labour: Data obtained from National Survey, 2007. [cited 20 July 2015] Available at URL: http://www.path.org/ publications/files/MCHN_popphi_amtsl_rpt_uganda.pdf

20. Kramer MS, Berg C, Abenhaim H, Dahhou M, Rouleau J, Mehrabadi A, Joseph KS. Incidence, risk factors, and temporal trends in severe postpartum hemorrhage. Am J Obstet Gynecol. 2013;209:449. e441-447.

21. Allen VM, O'Connell CM, Liston RM, Baskett TF. Maternal morbidity associated with cesarean delivery without labor compared with spontaneous onset of labor at term. Obstet Gynecol. 2003;102:477-82.

22. Liu S, Heaman M, Joseph KS, Liston RM, Huang L, Sauve R, Kramer MS, Maternal Health Study Group of the Canadian Perinatal Surveillance S. Risk of maternal postpartum readmission associated with mode of delivery. Obstet Gynecol. 2005;105:836-42.

23. Hager RM, Daltveit AK, Hofoss D, Nilsen ST, Kolaas T, Oian P, Henriksen T. Complications of cesarean deliveries: rates and risk factors. Am J Obstet Gynecol. 2004;190:428-34.

24. Al-Zirqi I, Vangen S, Forsen L, Stray-Pedersen B. Prevalence and risk factors of severe obstetric haemorrhage. BJOG. 2008;115:1265-72.

25. Joseph KS, Rouleau J, Kramer MS, Young DC, Liston RM, Baskett TF, Maternal Health Study Group of the Canadian Perinatal Surveillance S. Investigation of an increase in postpartum haemorrhage in Canada. BJOG. 2007;114:751-9.

26. Okeke T, Ekwuazi K. Is there Still a Place for Vacuum Extraction (Ventouse) in Modern Obstetric Practice in Nigeria. Ann Med Health Sci Res. 2013;3:471-4.

27. Stones RW, Paterson CM, Saunders NJ. Risk factors for major obstetric haemorrhage. Eur J Obstet Gynecol Reprod Biol. 1993;48:15-8.

28. Calvert C, Ronsmans C. HIV and the risk of direct obstetric complications: a systematic review and meta-analysis. PLoS One. 2013;8:e74848.
29. Curtis M, El Ayadi A, Mkumba G, Butrick E, Leech A, Geissler J, Miller S. Association between severe obstetric hemorrhage and HIV status. Int J Gynaecol Obstet. 2014;125:79-80.

30. Sloand EM, Klein HG, Banks SM, Vareldzis B, Merritt S, Pierce P. Epidemiology of thrombocytopenia in HIV infection. Eur J Haematol. 1992;48:168-72.

31. Bastin N, Tamayo OW, Tinkle MB, Alvarez Amaya M, Trejo LR, Herrera C. HIV disease and pregnancy. Part 3. Postpartum care of the HIV-positive woman and her newborn. J Obstet Gynecol Neonatal Nurs. 1992;21:105-11.

32. Uganda Demographic and Health Survey 2011. Kampala, Uganda: UBOS and Calverton, Maryland: ICF International Inc. [cited 20 February 2015] available at URL: http://www.measuredhscom/pubs/pdf/PR18/PR18.pdf

\section{Submit your next manuscript to BioMed Central and we will help you at every step:}

- We accept pre-submission inquiries

- Our selector tool helps you to find the most relevant journal

- We provide round the clock customer support

- Convenient online submission

- Thorough peer review

- Inclusion in PubMed and all major indexing services

- Maximum visibility for your research

Submit your manuscript at www.biomedcentral.com/submit

) Biomed Central 